\title{
Librarian Role-Playing as a Method for Assessing Student Information Literacy Skills
}

\author{
Soo Young Rieh \\ University of Texas at Austin, \\ Austin, TX, USA \\ rieh@ischool.utexas.edu
}

\author{
Doreen Bradley \\ University of Michigan Library, \\ Ann Arbor, MI, USA \\ dbradley@umich.edu
}

\author{
Emma \\ Brennan-Wydra \\ University of Michigan, \\ Ann Arbor, MI, USA \\ ebwydra@umich.edu
}

\author{
Marley Kalt \\ University of Michigan, \\ Ann Arbor, MI, USA \\ marleyk@umich.edu
}

\begin{abstract}
Researchers and practitioners alike have long investigated the effectiveness of information literacy instruction, addressing what to measure regarding student learning and how to measure it. The purpose of this paper is twofold. First, we review measures and methods that have been developed to assess student learning that results from information literacy instruction. We then present a study in which we employed a new research method of librarian role-playing to examine the extent to which college students are capable of demonstrating their information literacy skills while acting as an academic librarian. We also incorporated card-sorting exercises, asking about their perceived search difficulty before and after the role-playing exercise. Ten role-playing sessions were conducted by recruiting undergraduate students who had attended an information literacy instruction session 3-4 months prior as a part of their English writing course. Results showed that the librarian role-playing method provided opportunities for participants to recall and reflect upon what they learned from information literacy instruction effectively. Results also indicated that the role-playing method is potentially effective in developing students' meta-cognition about their search behavior.
\end{abstract}

\section{KEYWORDS}

Methods and Measures in Information Literacy Instruction; Method for Assessing Student Learning in Library Instruction; Role-Playing in Information Literacy

82nd Annual Meeting of the Association for Information Science \& Technology I Melbourne, Australia I 19-23 October, 2019

Author(s) retain copyright, but ASIS\&T receives an exclusive publication license

DOI: $10.1002 /$ pra2.00018

\section{ASIS\&T THESAURUS}

Research Methods; Library User Instruction; Information Behavior

\section{INTRODUCTION}

There has been substantial discussion and research among library practitioners and library and information science researchers alike about what to teach and how to deliver information literacy instruction. Researchers and practitioners have also investigated the effectiveness of instruction, focusing on two research problems: what to measure regarding student learning in information literacy instruction and how to measure it. The first problem, what to measure, raises differing views concerning criteria and measurements of information literacy. Often this debate is related to how information literacy is defined: as a set of skills, or as concepts that enable critical thinking (Lloyd, 2010). Researchers and librarians have attempted to identify qualitative measures based on reflective narratives that can assess students' higher-level cognitive learning in ways that go beyond quantitative information literacy measurements (McKinney \& Sen, 2012). In 2016, the Association of College and Research Libraries (ACRL) adopted the Framework for Information Literacy for Higher Education, taking a new direction in information literacy instruction as it moved away from its previous focus on locating, evaluating, and using information and began emphasizing meta-cognitive processes such as self-reflection and recognition of information value. To address the second research problem, how to measure student learning resulting from information literacy instruction, a number of research methods have been developed and employed over the years. Pre- and post-instruction surveys, individual interviews, focus group interviews, evaluation of student assignments or quizzes, and lab-based experimental studies have been widely used (Markey, Leeder, \& Rieh, 2014). 
Although there have been active discussions and studies regarding what to measure and how to measure student learning as a result of receiving information literacy instruction, many measures and methods have focused on investigating the impact of information literacy instruction through selfreports (e.g., surveys, questionnaires, interviews) or implicit indicators (e.g., quizzes, assignments, and lab-based experimental studies). However, these measures or methods may not offer sufficient evidence to demonstrate students' ability to conduct library research while also recalling, reflecting on, and articulating what they have learned from information literacy instruction.

This research problem led us to design an alternative research method that adopts librarian role-playing as a technique for investigating the extent to which students are capable of demonstrating their information literacy skills while acting as an academic librarian. Role-playing is an activity in which "participants act out a set of defined role behaviors or position with a view to acquiring desired experiences" (Sogunro, 2014, p. 356). Specifically, we asked study participants to act as librarians giving instructions to an incoming college student about how to use the academic library system in order to find scholarly articles to prepare for a writing placement test. We also incorporated card-sorting exercises, asking about the perceived difficulty of seven different types of search behavior before and after completing the role-playing task. We developed the librarian role-playing method to assess student learning in information literacy instruction because we believe that this method offers researchers and practitioners the potential to measure students' information literacy skills and perceptions of difficulty more accurately than other research methods used in previous work.

Role-playing has long been used as a training method for nurses, salespersons, and classroom teachers (Martinez Riera, Cibanal, \& Mora, 2010) because of its ability to impart effective problem solving skills as well as insight, sensitivity, and awareness. Role-playing offers learners the opportunity to associate enacted roles, attitudes, and behaviors with real-life situations (Sogunro, 2004). From a teaching perspective, it emphasizes different points of view by enabling participants to examine their own behavior while experimenting with new attitudes (Carlomagno, Di Tore, \& Sibilio, 2014).

In the field of library and information science, Mess (1994) introduced role-playing exercises as an instructional technique and discussed how "interactive modules" (p. 115) that adapt role-playing can be used for library instruction in a classroom setting. Sheets (1998) used role-playing to train student library assistants by placing a student assistant at the reference desk and having a librarian act as a patron by approaching the desk and asking a reference question. However, to the best of our knowledge, there has been no previous research on using role-playing as a method of assessing students' information literacy skills in conjunction with information literacy instruction.
The motivation for this research is our belief that it is important to develop a novel and performative research method to assess college students' abilities to search for and evaluate information in library systems that goes beyond studying the effectiveness of information literacy instruction programs. It is commonly understood that being able to teach a concept is a solid indicator of mastery of that concept. Therefore, evaluating how well students are able to take on the role of a librarian who teaches concepts involved in searching for and evaluating information is a creative and effective method.

The purpose of this paper is twofold. First, we review a variety of measures that have been developed and methods that have been employed to assess student learning that results from library instruction. We then present a study examining the benefits and drawbacks of librarian role-playing as a new research method that can be used to demonstrate students' information literacy skills. In this paper, we are particularly focused on students' information literacy skills with respect to searching for and evaluating information when using an academic library system. This paper addresses three research questions:

1. To what extent do college students recall and reflect on the learning they gain from an information literacy instruction session when they engage in librarian role-playing?

2. How do college students feel when they play the role of academic librarian to demonstrate their search behavior using an academic library system?

3. What are the benefits and drawbacks of using the librarian role-playing method to assess information searching and evaluation skills?

\section{MEASURING LEARNING OUTCOMES IN INFORMATION LITERACY}

Conceptualizing information literacy has long been a topic of discussion among librarians, faculty, and institutions of higher education. Notions of what constitutes information literacy continue to evolve, as do the methods used to measure student abilities. Information literacy is considered foundational to life-long learning. Cultivating the ability to find, understand, evaluate, and synthesize information is essential to learning within and beyond an academic curriculum. Information literacy is sometimes associated with competence in a set of skills, such as the Information Literacy Competency Standards for Higher Education, which can be discretely taught and measured (ACRL, 2000). The scholarly conversation shifts significantly with the discussion of information literacy in terms of a series of six frames through which students understand the theory and practice of information and its use (Bruce, Edwards, \& Lupton, 2006).

Lloyd (2010) explores this dichotomy of whether information literacy is a skills-based literacy or a critical thinking process that serves as a catalyst for learning. Lloyd argues that context is a critical element of information literacy, lending more credence to the developing notion that information literacy is more conceptually based, rather than a set of independent 
skills. ACRL rescinded its original Information Literacy Competency Standards for Higher Education (ACRL, 2000) and replaced them with the highly conceptual Framework for Information Literacy for Higher Education (ACRL, 2016). With this framework, ACRL significantly moved the pendulum on the skills vs. conceptual debate on a national scale. Gone are the specific skills and in their place are knowledge practices and dispositions for each of six frameworks that information literate students should demonstrate. It suggests a framework within which librarians and faculty can collaborate to teach information literacy and firmly embeds information literacy in the scholarly process. While there are certainly skills that students should master, the core of the current information literacy debate is clearly centered in a conceptual model.

The Information Literacy Competency Standards for Higher Education (ACRL, 2000) presented an extensive list of skills that were incorporated into assessment projects. Assessing the construction of a search strategy or the selection of an appropriate database for a given topic are measurements that are easy to conduct and replicate. Many studies also seek to assess skills or factual knowledge at a very granular level, such as using the library catalog and academic databases to conduct searches (e.g., Bryan \& Karshmer, 2013; Zhang, Goodman, \& Xie, 2015). There are also numerous studies that assess students' skills in evaluating sources of information based on credibility (Bryan \& Karshmer, 2013; Hess, 2014; Hufford, 2010; Zhang et al., 2015).

Studies investigating changes in behavior following library instruction have included questions about using library resources and conducting searches (Hess, 2014; Zhang et al., 2015), while commonly measured student attitudes include levels of research confidence or self-efficacy (Brennan-Wydra \& Culler, 2019), comfort using or getting help from the library (Hess, 2014), and information anxiety (Halpern, 2016) before and after intervention.

With the adoption of the Framework for Information Literacy for Higher Education (ACRL, 2016), the road has been paved for many new methods that can assess information literacy at the conceptual level. In addition to quantitative measures, librarians may also look at qualitative measures using reflective evaluation measures and other processes that can assess students' higher-level reasoning and decision making. The ACRL Framework for Information Literacy Sandbox is designed to aid librarians in designing activities and assessments to measure student learning outcomes using the new framework (ACRL, 2017). As the ACRL Framework is adopted at institutions across the country, more studies will be designed to assess the conceptual approach to information literacy.

\section{RESEARCH METHODS USED IN PREVIOUS WORK Pre- and Post-test Surveys}

Pe7rhaps one of the most widely used methods of measuring what students learn from library instruction is pre- and post- instruction surveys. Surveys are an appealing assessment tool because they allow researchers to collect data from a relatively large number of participants with little effort on the part of either the researchers or the participants, and because the quantitative data obtained from multiple-choice survey questions can be analyzed quickly and easily using appropriate statistical techniques. Administering surveys to students before (pre-test) and after (post-test) they attend library instruction sessions allows researchers to draw empirical conclusions about how student knowledge, behaviors, and/or attitudes changed across the period of data collection. These surveys may be administered across multiple modes, including online (Halpern, 2016; Hess, 2014), and on paper (Bryan \& Karshmer, 2013). The amount of time between the administration of the preand post-test surveys varies widely among studies, from less than an hour to several months (Hufford, 2010).

Data collected from student surveys are most often analyzed using descriptive statistics, such as percentages and averages, to identify differences between students' responses before and after receiving library instruction. As noted by Walker and Pearce (2014), however, descriptive statistics can provide some insight into student learning but cannot determine whether or not changes in student responses were statistically significant. A smaller number of studies (Bryan \& Karshmer, 2013; Halpern, 2016) have used inferential statistics in a formal hypothesis testing framework, such as $t$-tests and analysis of covariance (ANCOVA), to obtain more conclusive and generalizable results. Surveys have been used to assess not only the efficacy of single library workshops (Hufford, 2010) but also relative gains from different instructional formats (Bryan \& Karshmer, 2013; Hess, 2014).

One major drawback of using surveys to understand and assess student learning is that the closed-ended, multiple-choice questions commonly employed may be too simplistic to accurately capture student learning. To combat this drawback, several studies have combined surveys with additional modes of data collection. For example, Mery, Newby, and Peng (2011) used a threephase study design to assess the impact a library-based course had on students' information literacy skills: (1) collection of qualitative data via focus groups, reflection papers, and discussion forums; (2) collection of quantitative data through pre- and post-test surveys; and (3) evaluation of the quality of student work. In addition, Zhang et al. (2015) supplemented the quantitative data obtained from pre- and post-test surveys with qualitative data from two student focus group sessions consisting of openended questions about an online library instruction module. Combining quantitative survey data with other sources of information provides evidence of construct validity for home-grown survey instruments and provides a more complete picture of student experiences in information literacy instruction sessions.

\section{Individual and Focus Group Interviews}

Interviews and focus groups are more resource-intensive than other methods, meaning that the financial and time investments 
required to conduct interviews can be prohibitive. In some cases, researchers have attempted to conduct information literacy-related interviews but later abandoned the method due to time and resource constraints (Emmett \& Emde, 2007). However, interviews and focus groups do provide additional insights into information literacy assessment that cannot be gained by static methods such as surveys. Interviews add an extra dimension to understandings of students' abilities, providing additional indicators of student knowledge (Dunn, 2002; Emde \& Emmett, 2004). Asking students in person about search behaviors gives researchers the opportunity to witness meaningful steps that students take, which may reveal students' competencies beyond self-reports. In-person interactions can also be seen as a way to emphasize the importance of information literacy and cultivate relationships between students and librarians, thereby serving an educational purpose beyond that of assessment (Emmett \& Emde, 2007).

A few studies have introduced a performance-based element into assessment interviews for information literacy. Dunn (2002) explored scenarios as part of a multi-year assessment of California State University core competencies, which mapped closely onto ACRL standards for information literacy. Depth and breadth of student understanding were found to be associated, and student proficiency was found to be relatively steady across competencies. In another performance-based interview, Emde and Emmett (2004) conducted a withinsubjects study in which students were interviewed at the beginning and end of a semester. Students were presented with information seeking scenarios during the interviews, including how to navigate the library website and find items using the library catalog. Student performance at the beginning of the semester was compared to performance at the end and was overall found to have improved over the course of the semester.

Across studies, interview and focus group methodologies have proven valuable as means of dynamically assessing information literacy. The interpersonal nature of interviews and focus groups allows researchers to observe the process through which students reason about information, providing potentially richer insights than those provided by static surveys.

\section{Student Assignments and Quizzes}

Evaluation of student assignments completed in relation to library instruction sessions has been used as a technique for assessing student learning. Examples of student assignments include student research papers (Cooke \& Rosenthal, 2011; Gamtso \& Paterson, 2012; Luetkenhaus, Hvizdak, \& Johnson, 2017), student worksheets administered as part of the instruction session (Matlin \& Lantzy, 2017), and quizzes (Lowe, Boothe, \& Tagg, 2014). Evaluation of student research papers is the most common way that this assessment technique has been implemented. Gamtso and Paterson (2012), for example, examined students' final papers written as part of a three-workshop series in which students were asked to solve a problem working as a group in collaboration with librarians, researchers, and instructors. Analysis of these final papers revealed students' ability to apply critical thought and provide well-crafted recommendations, indicating that this collaborative, active-learning exercise helped students move beyond merely learning information retrieval skills to learning how to analyze and apply information. Similarly, Luetkenhaus et al. (2017) used students' final research papers to measure the impact of library instruction for first-year students, having raters from across the library provide feedback on students' demonstration of information literacy skills. Cooke and Rosenthal (2011), on the other hand, took a slightly different approach to analyzing student research papers, examining the citation pages of the papers as opposed to the content. They found richer bibliographies among students who had received library instruction.

Another way student assignments have been integrated is by making them part of the library instruction session itself. Matlin and Lantzy (2017), for example, used a backwards instructional design process to identify learning outcomes and created library assignments accordingly to measure achievement of those outcomes from in-person vs., online library instruction. These assignments had students practice basic library skills, such as finding articles via library databases using relevant keywords and generating properly formatted citations, while also reflecting on the differences between scholarly literature and popular sources. The researchers found this method to be fruitful in eliciting student responses but did not find statistically significant differences between the online and in-person groups.

Researchers have also used testing and quizzes as a method for assessing student learning from information literacy instruction. Lowe et al. (2014), for example, developed a quiz that was integrated into an online information literacy tutorial at their library. They reported that this quiz provided valuable insights into first-year students' information literacy skills over time, which in turn increased librarians' ability to tailor student instruction.

\section{Lab-based Experimental Studies}

Experimental studies are not very prevalent in the literature assessing the impact of library instruction. When experimental studies appear in the library instruction literature, they often employ a pre-test and post-test design (e.g., responses are measured before and after the intervention and then compared) (Koufogiannakis \& Wiebe, 2006; Van Scoyoc, 2003), but may also use a post-test only design (Mery, DeFrain, Kline, \& Sult, 2014; Salisbury, Omolewu, \& Smith, 2018). Experimental studies have been used in a variety of ways, including to test different library instruction methods (Mery et al., 2014), measure which type of instruction best alleviates library anxiety (Van Scoyoc, 2003), and quantify the effect of cell phone use during library instruction sessions (Salisbury et al., 2018).

Experimental studies can be difficult to implement in library instruction assessment because researchers usually only have 
access to participants who have already been formed into groups, such as university classes, rather than a subject pool of individuals who can be randomly assigned to different groups (Koufogiannakis \& Wiebe, 2006). Due to these limitations, experimental studies in library instruction assessment typically apply randomization to entire groups of participants, for example, by randomly choosing which classes are in the control and which are in the treatment group, rather than randomly assigning individual participants to treatment or control groups (Koufogiannakis \& Wiebe, 2006; Salisbury et al., 2018; Van Scoyoc, 2003).

\section{ROLE-PLAYING AS A METHOD OF ASSESSING STUDENT LEARNING IN INFORMATION LITERACY INSTRUCTION}

\section{Data Collection}

To investigate student learning in library instruction sessions, we designed our research in two phases. The students who participated in the study were undergraduate students in multiple sections of an English "writing and academic inquiry" course at a Midwestern research university in the Fall 2018 semester, the majority of whom were in their first year of college.

In Phase I, pre- and post-session online surveys were disseminated across eleven one-shot library instruction sessions taught by the same librarian. The pre-session survey was administered in class by displaying the survey link on-screen right before the library instruction was given, and the postsession survey was administered by contacting the students by email about two weeks later. Ten questions in the surveys focused on three areas of college-level information literacy: conducting searches, evaluating sources, and navigating the university library system. The results of paired $t$-tests for students who completed both surveys $(\mathrm{N}=45)$ revealed areas in which respondents showed the greatest pre- and post- differences: how to get to articles using the library website (Mean change $=+1.73, \mathrm{t}(36)=10.07, p<.001)$; how to use the library to do research (Mean change $=+1.35, \mathrm{t}(36)=7.40$, $p<.001)$; and how to get research help from the library (Mean change $=+1.27, \mathrm{t}(36)=6.89, p<.001$ ) (BrennanWydra \& Culler, 2019). The areas in which respondents did not report improvement were persistence in searching, credibility assessment, and relevance judgment (BrennanWydra \& Culler, 2019). However, this method relied on gathering data about students' self-reported confidence levels. With pre- and post-session survey responses alone, we were not able to identify specific areas in which students struggled most in performing library research.

Being aware of the limitations in the results from Phase I, we decided to design another phase of the study that would allow us to supplement our quantitative data from student surveys with additional data coming from three different sources: (1) librarian role-playing; (2) card sorting exercises on perceived difficulty in various kinds of search behavior prior to role-playing and afterwards; (3) an opening interview and an exit interview. Figure 1 displays the procedures for each session.

In the Spring 2019 semester, we emailed 159 students who completed a pre-session survey in Phase I, inviting them to participate in the Phase II follow-up study. For the roleplaying component, we began with a short exercise about finding the location of classrooms using the university website, which took 2-5 minutes. This exercise was included to make participants more comfortable in the interview environment and did not factor into the assessment outcomes. Once study participants completed this short exercise, the librarian role-playing session began. Note that while participants were asked to play the role of a librarian, the researcher pretended to be an incoming first-year student who needed help from the librarian to find scholarly resources using the library system.

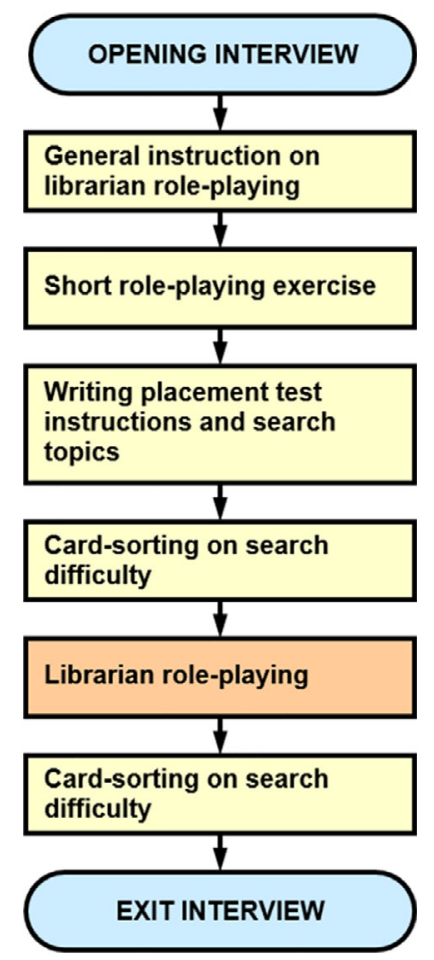

Figure 1. Data collection procedures.

The role-playing oral instruction given to study participants appears in Figure 2.

Next, we will have a section where I ask you to put yourself in the shoes of a librarian. I'll ask you to imagine yourself as a librarian, and you'll have the chance to demonstrate how you might help an incoming student who needs your help finding scholarly sources. For this portion of the interview, you are now a librarian. I am an incoming first year student, and I have a couple of questions about navigating the University and my coursework.

Figure 2. Librarian role-playing script. 
The researcher read the following script to participants: "I need to complete the placement test for writing before I start classes in the Fall, and have been given a few options for topics. I need to use scholarly sources, but am not sure where to start. Can you help me find at least 3-5 scholarly articles to use for my paper, on any one of these topics?" The researcher then gave out a paper copy of the "writing test instructions" to the participants. The instructions stated that all incoming students needed to write an academic essay in 1,200-1,500 words on one of four topics. The essay instructions read, "If you need any assistance completing your writing placement test, you are able to consult with a librarian to gain a better understanding of scholarly work and the research process."

Participants were asked to choose one topic out of four search topics for which they felt most comfortable finding information. All four search topics were real essay topics that one of the authors, who is a librarian at the university, received as reference questions from undergraduate students.

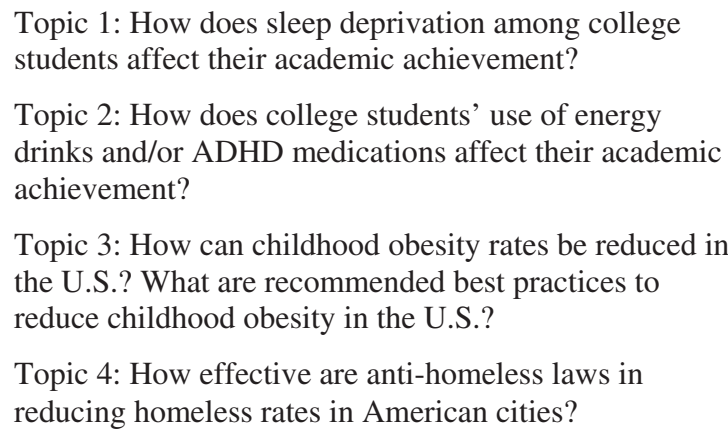

Topic 4: How effective are anti-homeless laws in reducing homeless rates in American cities?

Figure 3. Search topics given to study participants who played librarian role.

Another technique used in this study was card-sorting exercises (St. Jean, Taylor, Kodama, \& Subramaniam, 2018), which were administered before and after the role-playing exercise. The card sorting method was employed to compare participants' perceptions of difficulty in conducting searches and evaluating sources when using the academic library system. Participants were instructed to rank the content of each card on a difficulty scale of 1-5 by placing each card onto a sheet of paper with the difficulty level: $1=$ not at all difficult, $2=$ a little difficult, $3=$ somewhat difficult, $4=$ difficult and $5=$ very difficult. The seven cards were made using 3" X 5" cardstock. Before handing over the cards to a participant after the participant had selected a research topic, the researcher shuffled them to ensure they would be in random order. Each card contained a brief description of a different aspect of the search process:

- Figuring out where to start/where to look when beginning a search

- Thinking of keywords that will retrieve relevant information on my topic
- Judging the information with regard to its relevance

- Judging the information with regard to its trustworthiness/ credibility

- Differentiating scholarly articles from non-scholarly ones

- Using the university library to get full-text articles

- Choosing the best sources on the topic

Once participants placed each card on one of the printed scales, the researcher took a picture to record the choices. After the participants completed the role-playing exercise, they were asked if they wanted to move any of the cards from one point on the scale to another to see if their perception of task difficulty had changed.

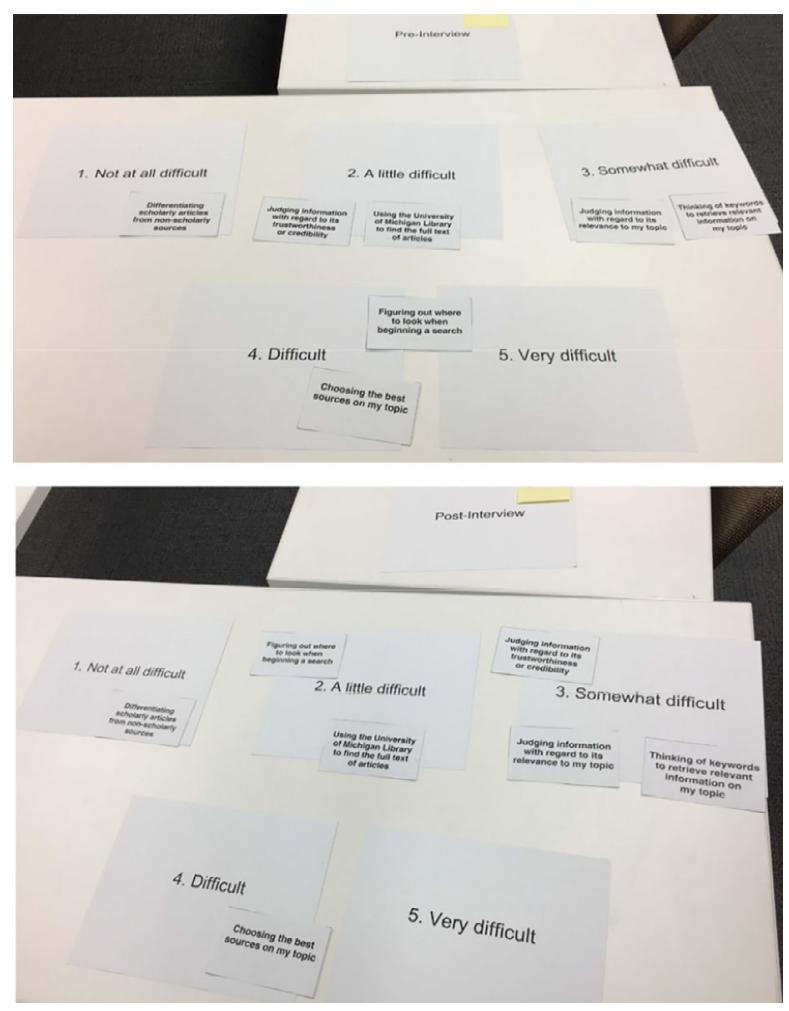

Figure 4. Card-sorting exercises.

Several interview questions were asked before and after the role-playing session. The opening interview included background questions about the year participants started at the university, their school/program, and their major. Two key questions asked at this stage were: (1) if they remembered anything from the library instruction session; (2) if the library instruction had changed the way they searched for information.

The exit interview questions included: (1) how did you feel during the search process? How did it feel to explain what you were doing to someone else?; (2) which part of the search process did you find most challenging to explain? Why?; (3) do you feel your searches were successful? Why or why not?; (4) is this how you typically would search? Did you do something differently because you played the role of 
librarian?; (5) after you've done this, is there anything else about library research that you wish that you had learned from the instruction session?; (6) are there any concepts or skills related to library research that you would like to improve?; (7) is there anything else you want to tell us, or do you have any questions for us before we finish the interview?

The entire session, including the opening interview, cardsorting prior to the role-playing, searching during the role-playing, card-sorting after the role-playing, and exit interview were audio-recorded and fully transcribed for data analysis. Each session took about 35 minutes, ranging from 20 to 45 minutes. The average length of audio recording was 30 minutes. Participants were compensated US \$20.00 in cash for participation.

\section{Data Analysis}

The data were analyzed inductively through three phases. In the initial phase, we looked for ideas, issues, and patterns from the transcripts to develop codes. The initial codes included remembering library instruction session, takeaways from library instruction, reflection on library instruction, changes in search behavior after instruction, applying session content, demonstrating search skills, demonstrating information evaluation abilities, feeling during the search process, perception of successful search, confidence in searching, difficulty/challenges in role-playing, and general feeling about role-playing. In the second phase, we identified major categories by clarifying initial codes and merging some codes. The categories that emerged were recalling library instruction, reflection on library instruction, demonstrating/explaining search behavior, information literacy skills, role-playing experience, and value of role-playing. In the final stage, we aligned the categories with respect to our three research questions.

\section{RESULTS}

Out of 159 undergraduate students who completed a prelibrary instruction session survey in Phase 1, 10 students volunteered to participate in the role-playing sessions. All participants except one reported that they began their undergraduate program in 2018 and were in their first year of college at the time of the session. One person began in 2017. Their major/interest areas were diverse: neuroscience, computer science, biology, political science, industrial design, music, and nursing. Eight participants were female and two were male. They all attended one-shot library instruction sessions taught by the same librarian in the Fall 2018 semester, which were offered as a part of a "writing and academic inquiry" course. For all participants, it had been about 3-4 months since they had attended a library instruction session. In terms of search topics used in the role-playing session (see Figure 3), seven participants (P01, P03, P04, P06, P07, $\mathrm{P} 08$, and P10) chose Topic 1 (sleep deprivation), two participants (P05 and P09) searched on Topic 2 (use of energy drinks and ADHD medications) and one participant (P02) selected Topic 3 (childhood obesity). No participant chose Topic 4 (anti-homeless laws).
Research Question 1: To what extent do college students recall and reflect on the learning they gain from an information literacy instruction session when they engage in librarian role-playing?

Most participants were able to recall a few things covered in the information literacy instruction, and some were able to reflect on the content in detail. P09 seemed to recall key takeaways very well: "I remember the instructor...walked through... what good sources to use, like what differentiates a good source from a bad source and how to validate your argument basically with supporting sources and how to find them through the library's website." P02 said that she remembered "going through different databases and libraries that we have access to online," saying "it definitely showed me new ways to do (things) such as accessing the libraries online and librarians here were able to help us so much." Likewise, P01 recalled that the session "was pretty much everything about the (library) website," including "how you can talk to a librarian right on the website, how to get documents, the different search (data)bases you can go to, (and) advanced search versus just one line search."

In terms of reflecting on whether the library instruction changed the way that they search for information, most participants were now less likely to rely on Google and more likely to turn to the academic library system and even use advanced search features. P10 responded that "I'm a lot less hasty now... and I delve more into, I don't pick the first one on the page...I like to go down and I know... what proper sources are." P02 reported that if she had not had the instruction, "probably I would have reached out to friends for advice versus talking to the librarians and using all the online resources they had." P06's reflection was that "it would have taken me longer to find sources if I were...either Googling them or not using the advanced searching techniques." P01 has been applying the content of the session to her other coursework, noting that she has been using library databases "probably daily, searching for things" as she works on a final paper for a women's studies class. When it comes to searching for scholarly articles, P01 said, "I would never just use Google. I always just use (the university library) database (because) I think it's way more successful (and) it's just so much easier for me to use."

In summary, participants of our study could recall what they learned from one-shot library session which they attended 3-4 months ago. Information literacy topics mentioned frequently by participants were source evaluation, accessing library databases, and navigating the university library system. Most participants reported that the library instruction made a difference in the ways that they search for information for academic purposes as they became more likely to use the library system.

Research Question 2: How do college students feel when they play the role of academic librarian to demonstrate their search behavior using an academic library system? 
All participants, except P07, reported that they did not have difficulty in playing the role of academic librarian. P05's reaction was that "it was pretty easy. I felt like it was not very stressful" when he had to explain his search process to someone else. P04 said, "I personally love teaching, so it was just a thing I like to do." P01, on the other hand, said that "there was a lot of pressure to be sure that you're hitting on the points, and you're communicating well enough. But I feel like I mostly know what I'm doing." P07 was the only participant who found the role-playing difficult: "I mean it just felt weird because you're not actually a freshman." P07 also responded that "it was kind of difficult to be thinking about what to say next and, you know, helping that person."

One potential problem was that participants might change their search behavior because they were playing the role of a librarian. Most participants, except P08, responded that they did not search differently because of the role-playing. P03 and P09 were explicit about it, saying they would do exactly the same thing without having played the role. P01 said that aside from the choice of topic, "this was exactly how I would do my search." In the case of P08, she used the databases from the library a lot more because of the role given to her. Otherwise, she would have turned to Google and Wikipedia.

Some participants seemed to embrace the idea of being a librarian. P10 gave advice that sounded like what a real librarian would say: "Definitely don't be afraid to ask a librarian. I've asked a lot of times for help in finding good sources." P09 also encouraged students to find help in the library, saying "I would definitely tell an incoming student to ask questions if you're confused...because you don't want to write a paper that (is) either using articles that don't support your argument or worse comes to worse, plagiarizing because you don't know how to cite articles or what kind of articles to use and things like that." It was interesting to note that some participants seemed to internalize the librarian's experience when P01 somewhat jokingly stated, "Don't hire me as a librarian, okay?" when searching was not quite going as she initially planned and "I'm failing as a librarian right now" during the short role-playing exercise of finding classrooms on the university website. P02 was eager to promote librarians and the library during the role-playing exercise: "Good places to start are you can come to the librarians here and talk with them, you can email them, there is online chat so you don't even have to come in person, you can talk to the librarian there to ask them where to begin." P04 also pointed to the feature of getting help, saying "there's contact by email, call, text, but it looks like they make it pretty easy for you to contact them about anything."

The research design of librarian role-playing was well received by the vast majority of participants. These students seemed to feel comfortable acting as a librarian while demonstrating and explaining how to search information in the university library system. Further, they were able to take librarian's viewpoints and attitudes rather quickly.
Research Question 3: What are the benefits and drawbacks of using the librarian role-playing method to assess information searching and evaluation skills?

One of the benefits of this method was to give participants an opportunity to think more actively and critically about their own search behavior. According to P06, this method made him actively think throughout the whole session: "It definitely felt different just because, normally when I'm researching, it's not like I'm actively thinking about everything that I'm doing. I'm kind of just sort of clicking through...it's kind of like when you're driving on autopilot, and you don't really realize how you got somewhere, but you're there."

This method also gave participants opportunities to be conscious about making relevance and credibility judgments. P02 emphasized the importance of making relevance judgments when she said, "You can browse through (the source you found) a little bit to see if it's still relevant to your topic." Both P05 and P09 illustrated a difference between choosing "relevant" sources and "best sources." P09 explained her strategies of choosing "best sources" in detail by saying "I feel like most of the time you get a lot of evidence that you could use in your paper, but you need to pick which ones are going to validate your argument the most...That's a little bit difficult to differentiate." P05 was even more explicit about differentiating best sources from relevant sources than $\mathrm{P} 09$ when he engaged in the card-sorting exercise: 'I think, sometimes, you'll just read information and as soon as you see something that's at all relevant, you're just gonna choose that, whereas you need to spend a little bit more time deciding which sources are gonna be your best."

The combination of the role-playing and repeated card-sorting exercises was useful in identifying challenging areas for students in their search process (Figure 4). For instance, P08 said that explaining whether a source is credible would be the hardest part because credibility assessment is something that people have to decide on their own. In contrast, P01 found that judging information with respect to credibility or trustworthiness was easier than she expected, while making decisions about which database to use and how to filter the results had been the most difficult aspects of the search process both to execute and to explain. To P10, "it's going to be so hard to figure out where to start" even after she completed the roleplaying session. Likewise, P06 also responded that "figuring out where to look when beginning a search, I'd say that's still the hardest part. I kind of went down that path that I wasn't initially sure what to do the first time when I looked at the research guides and I decided that wasn't the right route for me, so I guess I'd keep that one as being somewhat difficult."

Another benefit of this method was that participants could get an accurate picture of how much they knew about searching in the library system. For instance, P03 acknowledged that she had "more of a surface level knowledge" about library databases than she initially thought, saying "it was harder (be)cause I think that I realized I didn't know as much as I thought about the databases." The role-playing method also 
revealed the misunderstandings that some participants had about how the library system and databases worked. As a result of doing the role-playing, P10 decided to lower her rating from 3 (somewhat difficult) to 2 (a little difficult) for the card which asked how difficult differentiating scholarly articles from non-scholarly ones because she felt she became "more familiar with the library resources." However, her reasoning was not necessarily accurate when she said, "I would think anything on the library website would be a scholarly article...If I were to just go there (the library system), that would be where I could find a lot of scholarly sources. So, it's much easier than like thinking how Google would do."

We found that role-playing offered our participants a unique opportunity to examine their own search behavior. As a result of role-playing, they became more aware of their knowledge, skills, and attitudes with respect to searching for and evaluating information in a library setting.

\section{CONCLUSION}

In this paper, we reported on the results of a study in which we investigated a proof-of-concept of a librarian role-playing method that could potentially be useful in assessing student learning resulting from information literacy instruction. The benefits of this method can be summarized as follows: First, the librarian role-playing method provided opportunities for participants to recall and reflect upon what they learned from an information literacy instruction session effectively. While acting as an academic librarian, some participants demonstrated behavior indicating that they internalized the experience of being a librarian and seemed to enjoy being in 'teaching mode.' Compared to a think-aloud method that asks people to articulate their action, thinking, and decision-making as they search (Kelly, 2009), role-playing seemed to make participants less "awkward and unnatural" (Kelly, p. 85) when performing searches and explaining what they were doing and how they were doing it because the researcher was also playing the role of an incoming college student. One of the significant findings is that this method offered participants an opportunity to pay attention to their own thinking process and searching strategies. As one participant explained, instead of "driving on autopilot" (P06), participants engaged in articulating their thoughts about search actions with detailed explanations. This finding indicates that the role-playing method is potentially effective in developing students' meta-cognition about their search behavior.

There are several limitations to this study. The study was conducted with students who were enrolled in the same English course at one university. The sample size of study participants was small $(\mathrm{N}=10)$, and eight of them were female. We will need to collect and analyze more data using this method to be able to draw conclusive results regarding its benefits and drawbacks. There might be sampling bias as the 10 volunteers who agreed to participate in the follow-up study were students who might feel more confident about their information literacy skills than those who did not volunteer. In order to minimize that source of bias, we introduced our study in terms of interviews without specifying that there would be a role-playing component in the recruitment email. Another limitation of our research design is that it may have felt inauthentic to some participants as the role of an incoming college student was played by a graduate student research assistant. In a future study, we could recruit real incoming college students to fill this role so that participants who are acting as the librarian could feel more natural in the study setting.

In spite of the limitations of this study, we have made methodological contributions to the fields of library and information science, interactive information retrieval, and librarianship by developing a new method that could be used to assess college students' abilities to use library systems to search for and evaluate information, rather than relying on previous methods that tend to measure the effectiveness of an information literacy instruction program. Although we believe that librarian roleplaying could be used as a stand-alone research method, we are confident that this method would be more effective when incorporated into a repertoire of data collection methods such as questionnaires, interviews, quizzes, and lab-based experimental studies. In our study, additional methods such as repeated card-sorting exercises as well as opening interview and exit interview questions strengthened the benefits of the librarian role-playing method.

\section{ACKNOWLEDGMENTS}

This project was made possible in part by the Institute of Museum and Library Services (RE-95-17-0104-17). We thank Angie Oehrli for her feedback on earlier drafts. We are also thankful to the anonymous reviewers for their thoughtful comments.

\section{REFERENCES}

Association of College and Research Libraries. (2000). Information literacy competency standards for higher education. Chicago, IL: American Library Association. http:// hdl.handle.net/11213/7668

Association of College and Research Libraries. (2016). Framework for information literacy for higher education. Chicago, IL: American Library Association. http://www. ala.org/acrl/standards/ilframework

Association of College and Research Libraries. (2017). Framework for information literacy sandbox. American Library Association. http://sandbox.acrl.org/

Brennan-Wydra, E., \& Culler, T. (2019, May). What firstyear students learn from one-shot information literacy sessions and what (they think) they already know. Poster at LOEX Conference, Minneapolis, MN.

Bruce, C., Edwards, S., \& Lupton, M. (2006). Six frames for information literacy education: A conceptual framework for interpreting the relationships between theory and practice. Innovation in Teaching and Learning in Information and Computer Sciences, 5(1), 1-18. 
Bryan, J. E., \& Karshmer, E. (2013). Assessment in the oneshot session: Using pre- and post-tests to measure innovative instructional strategies among first-year students. College \& Research Libraries, 74(6), 574-586.

Carlomagno, N., Di Tore, A., \& Sibilio, M. (2014). Role playing and perspective taking: An educational point of view. International Journal of Digital Literacy and Digital Competence, 5(2), 49-58.

Cooke, R., \& Rosenthal, D. (2011). Students use more books after library instruction: An analysis of undergraduate paper citations. College and Research Libraries, 72(4), 332-343.

Dunn, K. (2002). Assessing information literacy skills in the California State University: A progress report. Journal of Academic Librarianship, 28(1-2), 26-35.

Emde, J., \& Emmett, A. (2004). Assessing information literacy skills in the real world: The good, the bad and the literate. Paper presented at the 4th Annual Brick and Click Libraries: An Academic Library Symposium, pp. 83-89.

Emmett, A., \& Emde, J. (2007). Assessing information literacy skills using the ACRL standards as a guide. Reference Services Review, 35(2), 210-229.

Gamtso, C., \& Paterson, S. (2012). Guiding students from consuming information to creating knowledge: A freshman English library instruction collaboration. Communications in Information Literacy, 5(2), 117-126.

Halpern, R. (2016). Active learning works! Until it doesn't: Measuring the effectiveness of activity-based learning exercises on information anxiety. Journal of Library \& Information Services in Distance Learning, 10(3-4), 242-253.

Hess, A. N. (2014). Online and face-to-face library instruction: Assessing the impact on upper-level sociology undergraduates. Behavioral \& Social Sciences Librarian, 33(3), 132-147.

Hufford, J. R. (2010). What are they learning? Pre- and postassessment surveys for LIBR1100, introduction to library research. College \& Research Libraries, 71(2), 139-158.

Kelly, D. (2009). Methods for evaluating interactive information retrieval systems with users. Foundations and Trends in Information Retrieval, 3(1), 1-224.

Koufogiannakis, D., \& Wiebe, N. (2006). Effective methods for teaching information literacy skills to undergraduate students: A systematic review and meta-analysis. Evidence Based Library and Information Practice, 1(3), 3-43.

Lloyd, A. (2010). Information literacy landscapes: Information literacy in education, workplace and everyday contexts. Oxford, England: Chandos Publishing.

Lowe, S. M., Boothe, C., \& Tagg, N. (2014). Integrating an information literacy quiz into the learning management system. Communications in Information Literacy, 8(1), 115-130.
Luetkenhaus, H., Hvizdak, E., \& Johnson, C. (2017). Measuring library impacts through first year course assessment. Communications in Information Literacy, 11(2), 339-353.

Markey, K., Leeder, C., \& Rieh, S. Y. (2014). Designing online information literacy games students want to play. Lanham, MD: Roman \& Littlefield.

Martinez Riera, J. R., Cibanal, J. L., \& Mora, M. J. P. (2010). Using role playing in the integration of knowledge in the teaching-learning process in nursing: Assessment of students. Texto Contexto Enferm, 19(4), 618-626.

Matlin, T. R., \& Lantzy, T. (2017). Maintaining quality while expanding our reach: Using online information literacy tutorials in the sciences and health sciences. Evidence Based Library and Information Practice, 12(3), 95-113.

McKinney, P., \& Sen, B. A. (2012). Reflection for learning: Understanding the value of reflective writing for information literacy development. Journal of Information Literacy, 6(2), 110-129.

Mery, Y., Newby, J., \& Peng, K. (2011). Assessing the reliability and validity of locally developed information literacy test items. Reference Services Review, 39(1), 98-122.

Mery, Y., DeFrain, E., Kline, E., \& Sult, L. (2014). Evaluating the effectiveness of tools for online database instruction. Communications in Information Literacy, 8(1), 70-81.

Mess, J. A. (1994). Use of roleplaying in bibliographic instruction. Science and Technology Libraries, 14(2), $105-118$.

Salisbury, L., Omolewu, A. O., \& Smith, J. J. (2018). Technology use for non-educational purposes during library instruction: Effects on students learning and retention of information. Science \& Technology Libraries, 37(3), 274-289.

Sheets, J. (1998). Role-playing as a training tool for reference student assistants. Reference Services Review, 26(1), 37-41.

St. Jean, B., Taylor, N. G., Kodama, C., \& Subramaniam, M. (2018). Assessing the health information source perceptions of tweens using card-sorting exercises. Journal of Information Science, 44(2), 148-164.

Van Scoyoc, A. (2003). Reducing library anxiety in first-year students: The impact of computer-assisted instruction and bibliographic instruction. Reference \& User Services Quarterly, 42(4), 329-341.

Walker, K. W., \& Pearce, M. (2014). Student engagement in one-shot library instruction. Journal of Academic Librarianship, 40(3), 281-290.

Zhang, Q., Goodman, M., \& Xie, S. (2015). Integrating library instruction into the course management system for a first-year engineering class. College \& Research Libraries, 76(7), 934-958. 